\title{
Safety studies with the University of Melbourne multichannel electrotactile speech processor
}

Robert S.C. Cowan, PhD, DipAud; Peter J. Blamey, PhD; Joseph I. Alcántara, BSc, DipAud; Peter A. Blombery, MD; Ian J. Hopkins, MD, FRACP; Lesley A. Whitford, BSc, DipAud; Graeme M. Clark, PhD, FRCS, FRACS

Human Communication Research Centre, University of Melbourne, Melbourne, Victoria 3002, Australia; Vascular Laboratory, Alfred Hospital, Melbourne, Victoria, Australia; Department of Neurology, Royal Children's Hospital, Melbourne, Victoria, Australia; Cochlear Pty. Ltd., Lane Cove, New South Wales, Australia

\begin{abstract}
Results of safety investigations conducted as an integral part of the development of a multichannel electrotactile speech processor (Tickle Talker ${ }^{\mathrm{TM}}$ ) are reported. Electrical parameters of the stimulus waveform, design of the electrode handset and cabling, and the electrical circuitry of the speech processor/stimulator and programming interface have been analyzed for potential risks. Constant current biphasic square pulses delivered to electrodes positioned on the skin surface over the digital nerve bundles were chosen to optimize the safety, comfort, and function of the electrotactile stimulus. The device was battery-powered, and the user circuit was isolated from earthreferenced sources. Each electrode was isolated by capacitive coupling, preventing DC leakage of current to the user circuit. Studies of finger temperature showed slight cooling of the skin on the fingers of both stimulated and unstimulated hands for individual subjects following electrotactile stimulation through the Tickle Talker. Subsequent analysis of finger and hand vascular circulation in five subjects showed slight reductions in hand blood flow in some individuals. The results did not demonstrate a significant mean decrease in hand or finger blood flow following electrotactile stimulation. No evidence of sympathetic involvement was found, nor were any changes in vascular structure of the hand such as those associated with Raynaud's disease found. Evidence suggests that the decrease in temperature found in the initial study may be due to a change in the ratio of blood flow between arteriovenous anastomoses and nutritive capillary beds. Studies of: 1) changes in mean threshold and comfortable pulse widths over time; and, 2) changes in tactual sensitivity as measured by hot/cold, sharp/dull, and two-point difference limen
\end{abstract}

Address all correspondence and requests for reprints to: Robert Cowan, Human Communication Research Centre, Department of Otolaryngology, University of Melbourne, 32 Gisborne Street, East Melbourne, Victoria 3002, Australia. discrimination, did not detect any systematic change in peripheral nervous system function following electrotactile stimulation. Analysis of electroencephalogram (EEG) recordings taken during electrotactile stimulation, and after relatively long periods of experience with the device did not show any pathological changes which might be associated with epileptic foci. In summary, no contraindications to long-term use of the Tickle Talker were detected in the studies performed.

Key words: electroencephalogram (EEG), electrotactile stimulation, hand blood flow, hearing impairment, multichannel electrotactile speech processor, plethysmograph temperatures, Tickle Talker ${ }^{\text {tm. }}$.

\section{INTRODUCTION}

Since the 1920 s, researchers and educators of the deaf have sought to develop sensory aids to assist communication for the hearing-impaired (1). Exploited sensory modalities have included vision, touch, and more recently, direct neuroelectric stimulation $(2,3,4)$. While improvements in open-set word, sentence, and conversational speech perception have been reported for both children and adults using cochlear prostheses $(5,6,7,8)$, the necessity of surgical intervention for implantation has led to a renewed interest in development of noninvasive means of providing sensory input, especially in the case of children (9).

Research has established that speech information may be conveyed as tactual patterns, and that this information can be integrated with input from vision or aided residual hearing to improve speech perception as measured by 
Journal of Rehabilitation Research and Development Vol. 29 No. 1 Winter 1992

feature, word, or sentence tests $(10,11,12,13,14)$. Tactual displays developed to date differ in number and location of transducer sites, type of speech information transmitted, and methods of encoding this information. Despite numerous reports evaluating feasibility and potential benefits available from vibrotactile or electrotactile devices, investigation of potential hazards arising from everyday use of these devices over long periods has been overlooked. This contrasts with cochlear implant development, which has included stringent biomedical safety studies required by the surgical procedure involved (15).

Although use of tactile devices involves no surgical risks, unforeseen problems may arise after prolonged use, especially in the case of young children. Despite the lengthy history of vibrotactile aid development, with few exceptions (16), evaluations have been of tactile users having relatively short periods of training and experience with vibratory stimulation. In addition, systematic studies establishing the safety of the vibratory stimuli used have not been reported. Psychophysical aspects of electrical stimulation have been examined in the development of electrotactile devices such as the Tacticon 1600, however no evaluation of long-term safety issues relating to use of this particular device has been reported $(17,18)$. Given that multichannel tactile devices are viewed as a potential alternative to cochlear implantation for some subject groups, a clear responsibility lies with the developers and manufacturers of tactile devices to ensure that they are not only effective as speech perception devices, but also biomedically safe for long-term use.

In 1985, Blamey and Clark (19) first described a wearable, battery-powered multiple-channel electrotactile speech processor (Tickle Talker ${ }^{\mathrm{T}}$ ), which used electrical stimulation of the digital nerve bundles in the fingers of the nondominant hand to present speech information. Novel features of this device were use of nerve bundle stimulation in contrast to stimulation of peripheral nerve end organs, and use of a formant-based speech processing strategy similar to that used in the University of Melbourne/Cochlear 22-channel cochlear implant. Psychophysical studies demonstrated that placement of electrodes on the skin overlying the digital nerve bundles resulted in a more comfortable sensation, with larger dynamic ranges than for electrical stimulation at other body sites (20). These findings were consistent with physiological studies showing nerve fiber stimulation to be characterized by different evoked sensations than stimulation of nerve end organs (21). The digital nerve bundles in one hand provided a spatially distinct and well-ordered series of stimulus sites. In addition, use of the fingers had the well-known advan- tages that tactual sensitivity is maximal at the fingertips, and that cerebral representational area is proportionately larger for the facial region and hands. The nondominant hand was selected to reduce the possibility of the device limiting everyday functions of the hands.

This report summarizes the results of safety studies which have been conducted as an integral part of the development and evaluation program of the Tickle Talker. Aims of the studies were to: 1) assess the possibility of risks inherent in the electrical nature of the stimulus and device; and, 2) establish the safety of the device for longterm use by examining possible changes in physiology following use over an extended period. Assessment of the stimulus and device focused on safety considerations in the electrical parameters of the stimulus waveform, design of the electrode handset and cabling, and electrical circuitry of the speech processor/stimulator and programming interface. The longer-term physiological assessments included consideration of: 1) possible effects of electrotactile stimulation on local tissue, as measured by changes in tactual sensitivity, finger temperature, and finger and hand blood flow; 2) possible effects on peripheral nervous system function as measured by changes in threshold and comfortable level pulse widths over time; and, 3) possible effects on central nervous system function as measured by changes in electroencephalograms (EEG) during or following electrotactile stimulation.

\section{SAFETY CONSIDERATIONS IN THE DESIGN OF THE DEVICE}

\section{Electrotactile stimulator}

The device has been described in detail in previous reports $(20,22)$. It consists of: 1) a wide-band omnidirectional microphone to receive speech input; 2) a speech processor/stimulator unit, in which speech features are extracted in a manner similar to that for the 22-channel cochlear implant (23); and, 3) an electrode handset which is used to present speech information to the user as a pattern of electrical stimulation. The microphone, speech processor and stimulator circuitry are powered by a single 1.5 volt AA alkaline cell, which gives from 8 to 12 hours of continuous use.

The handset includes eight electrodes $\left(49 \mathrm{~mm}^{2}\right)$, positioned in rings worn on the four fingers of the nondominant hand, and located directly over the digital nerve bundles on the two sides of each finger. Several different materials have been used for electrode construction, including stainless steel mesh, stainless steel sheet, and platinum tubing. A single conductive rubber electrode $\left(10 \mathrm{~cm}^{2}\right)$ is located 


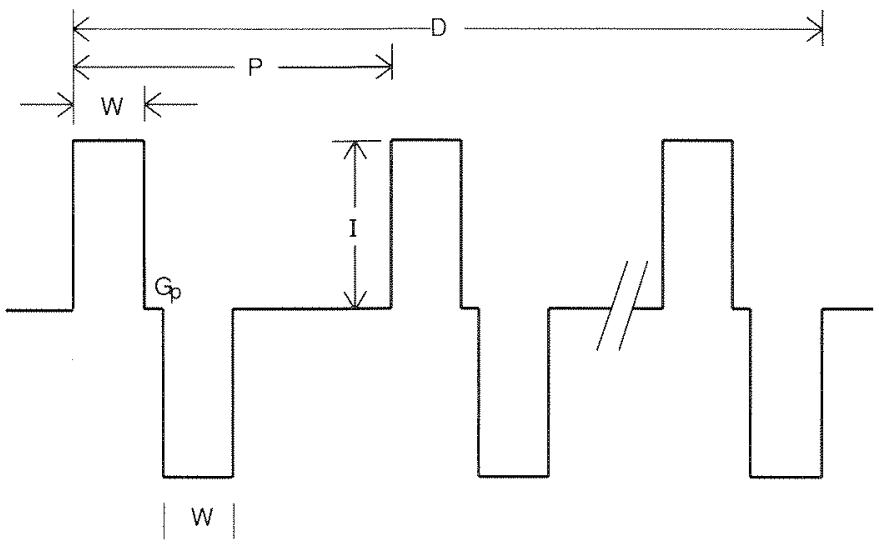

Figure 1.

Biphasic constant current stimulus waveform as used in the Tickle Talker $^{\text {TM }}: \mathrm{D}$ is the electrode stimulus duration; $\mathrm{P}$ is the period of each stimulus waveform; $\mathrm{G}_{\mathrm{p}}=100 \mu \mathrm{s}$, the interphase gap between two phases of the stimulus on any electrode; $I=1.5 \mathrm{~mA}$, the fixed stimulus current; $W$ is the pulse width of each phase of the biphasic stimulus over the range 10 to $1000 \mu \mathrm{s}$.

at the wrist. At any given time, current flows between one selected finger electrode and the wrist electrode. The electric current waveform (Figure 1) consists of biphasic, constant current $(1.5 \mathrm{~mA})$ square pulses. The two phases are separated by a $100 \mu \mathrm{s}$ gap in which there is no current flow.

Three speech features are extracted in the speech processor and presented as tactual patterns: 1) the main spectral peak between $800 \mathrm{~Hz}$ and $6,000 \mathrm{~Hz}$ (an estimate of vowel second formant frequency) is encoded as electrode position, with low frequency sounds presented on the index finger, and high frequency sounds such as $/ \mathrm{s} /$ on the little finger; 2) the speech amplitude envelope is encoded as pulse width of the biphasic pulses, and sensed by the user as changes in strength of stimulus; and, 3) the fundamental frequency is encoded as a scaled function of pulse rate, and sensed by the user as changes in the quality of sensation. A computer interface and RAM allows threshold (T) and comfortable (C) pulse widths to be set and programmed independently for each electrode over the range 10 to $1,000 \mu \mathrm{s} / \mathrm{ph}$ ase. The processor also allows the pulse rate to be scaled so that a fundamental frequency of $250 \mathrm{~Hz}$ results in a pulse rate of $150 \mathrm{pps}$. Scaling of pulse rate was based on psychophysical studies which showed better discrimination of pulse rate changes at lower rates of stimulation (20).

\section{Electrical stimulus considerations}

For safe and painless electrical stimulation of the skin, it is necessary to avoid irreversible electrolytic processes at the skin/electrode interface (24), dielectric breakdown resulting in a few high current density channels across the skin (25), and large conversion of energy to heat (26).

A biphasic constant current stimulus waveform with equal charge in each phase is used in the Tickle Talker to ensure that there is no net current flow, and to reduce the possibility of irreversible electrolytic effects at the skin/electrode interface. A biphasic rectangular pulse waveform was selected on the basis of previous studies demonstrating its safety for biomedical applications (27). Limiting of the electrode current applied in each phase to 1.5 $\mathrm{mA}$, flowing between the wrist and selected finger electrode, reduces the possibility of skin breakdown due to direct effects of the electrical stimulus. In addition, this level is well within established limits for electrical stimulation posing no danger to the myocardium $(28,29)$. The charge varied from $15 \mathrm{nC}$ to $1,500 \mathrm{nC} /$ phase as the pulse width varied from 10 to $1,000 \mu \mathrm{s}$, representing a maximum current density of $3.06 \mu \mathrm{C} / \mathrm{cm}^{2}$ geometric/phase. Biomedical safety studies of the University of Melbourne cochlear implant, using similar waveforms, have shown no damage to the neural tissue following prolonged intensive stimulation through implanted platinum electrodes with charge densities ranging from 20 to $40 \mu \mathrm{C} / \mathrm{cm}^{2}$ geometric/phase (30). Other studies of implanted electrodes used in subcutaneous stimulus regimes have suggested that all charge may be injected by reversible chemical reactions up to a maximum current density of $300 \mu \mathrm{C} / \mathrm{cm}^{2}$ geometric/phase (31). While care must be used in direct application of safety data developed for subcutaneous stimulation to the case of cutaneous stimulation, the charge densities used in the Tickle Talker are well below recommended safe levels (24).

The most direct method of controlling the charge applied to the skin is to use rectangular constant current pulses, in which the charge contained is a function of the current and pulse width (or duration) over which it is applied $(I \times W)$. The advantage of pulsed stimuli in contrast to sine wave stimuli is that the charge per pulse does not change with variations in repetition frequency (32).

\section{Design of the electrode handset and cabling}

In choosing a suitable metallic electrode material for use on the skin, limits are imposed due to physiological toxicity and mechanical strength. Two separate metallurgical problems exist, one being the necessary strength required of the electrode and connecting wire, and a second relating to electrolysis of electrodes in a fluid medium. Properties of the selected metal which are important will depend in the main on the particular application (33). In the case of the Tickle Talker, the electrodes must have robust mechanical and electrical stability, be biocompatible, 
Journal of Rehabilitation Research and Development Vol. 29 No. 1 Winter 1992

and able to pass adequate coulombic charge without electrolyzing tissue components. Although the mounting of the electrodes in the Tickle Talker handset is "dry," in that no electrolyte material is introduced to reduce skin electrical impedance, studies of dry electrode applications have indicated that small amounts of sweat accumulate quite rapidly on the skin surface under the electrode, and that for the purpose of establishing electrical contact with the skin, sweat is considered as a weak saline solution $(34,35)$.

Metals chosen for electrodes include noble metals such as platinum, activated iridium, and activated rhodium, and non-noble metals such as stainless steel, titanium, zirconium, and tantalum. Stainless steel is ideal for strength, although it may not be completely corrosion-resistant. In the case of monopolar electrical stimulation, it is necessary to use a more stable material such as platinum (i.e., resistant to electrolysis), while still having sufficient mechanical strength and good electrical conductivity. Use of bipolar current pulses has already been stressed as important in the limiting of possible electrolysis (21), and this stimulus waveform has been used in the design of the Tickle Talker. Electrodes used in a stimulation situation also differ from those used for recording in that they must operate at much higher current densities. Studies of electrode materials have shown that the current-carrying capabilities of stainless steel and platinum are intermediate, being less than for rhodium, but superior to copper or aluminum (36). In the design of the Tickle Talker handset, both stainless steel and platinum electrodes have been used successfully.

Selection of materials for the wrist ground electrode was based on consideration of electrical conductivity and biocompatibility. The use of a smaller active and larger indifferent electrode results in much higher current density under the active electrode, causing the stimulus effect to be localized in the vicinity of the active electrode (21). Previous studies of electrocutaneous stimulation have reported the possibility of "sudden stings," resulting from a breakdown in the high electrical resistance of the skin (37). Detailed examination identified the existence of large numbers of current pathways in parallel under large surface area electrodes. The sudden sting experienced by some subjects was suggested as being due to a large portion of current being shunted through a single skin pathway in which the high resistance was broken down. This was found to become more prevalent with larger electrode surface area. In the case of the Tickle Talker, some sensations have been experienced at the wrist electrode, possibly due to a similar breakdown in the high resistance which normally allows the current to be spread over multiple pathways. This may be the result of uneven contact between the larger return electrode and the skin, creating higher electrical conductivity at one particular point under the electrode, and reducing the effective area difference between the active and indifferent electrodes. This in turn could result in similar current densities under both electrodes, producing sensations at the wrist electrode. Wrist stimulation effects have been relatively infrequent, and have usually been eliminated by repositioning of the wrist electrode. The relatively high resistance of the conductive rubber electrode, as compared to metal, and the better contact area achieved due to its flexible construction, may also limit the potential for dielectric breakdown effects. Two subjects have also reported some transient contact allergic reaction to the particular rubber used in the electrode. This situation was corrected by substituting an alternative rubber electrode material. A long-term solution, the elimination of the indifferent wrist electrode, has been implemented in the present device. In this case, the seven "inactive" electrodes are connected together and used instead of the wrist electrode.

Locally generated heat due to electrical stimulation has been suggested as a potential problem, especially when electrodes are used on dry skin (38). Previous studies have shown that tissue heating effects are minimized as separation between the positive and negative phases of biphasic pulses approaches zero, since the energy stored in the skin capacitance by the first phase is removed by the second, instead of being discharged through skin resistance, thus creating heat (32). The Tickle Talker uses a relatively short $100 \mu \mathrm{s}$ gap between pulses that was introduced to increase the efficiency of the electrical stimulus pulses (20).

\section{Stimulator/interface electrical circuit design}

Assessments of potential risks inherent in the electrical design of the device included evaluation of the speech processor/stimulator circuitry, programming system, electrode handset and associated cabling. Electrical risk assessments were conducted for laboratory situations in which the device was attached to a mains-powered computer (i.e., during programming of the speech processor), and also for everyday situations in which the device was used as a wearable battery-powered speech processor. Independent biomedical engineering safety analyses of the firstgeneration prototype were also obtained from the Commonwealth of Australia, Department of Veterans' Affairs, and Department of Health, Medical Devices and Dental Products Branch.

Potential risks assessed included: accidental electric shock through breakdown of mains-powered equipment 
(laboratory), accidental overstimulation through breakdown of the speech processor circuitry (wearable device), accidental overstimulation through breakdown of the stimulator circuitry, and accidental overstimulation through misuse.

Design considerations incorporated into the device to eliminate or reduce potential risks included the following:

\section{Breakdown of Mains Equipment or Speech Processor Circuitry}

The computer was powered through a mains isolation transformer, and the stimulator was electrically isolated from the speech processor circuitry through an optoisolation linkage. Each of the electrodes in contact with the skin of the subject was connected to capacitors in series, thus limiting the possibility of DC current leakage between the subject and other equipment. In addition, a fused interface unit was included in the computer programming system to prevent passage of large current spikes to the equipment of the user while connected to the computer. The speech processor circuitry was waterproofed.

\section{Breakdown of Stimulator Circuitry}

The stimulator circuitry was designed such that failure of any one component could not result in accidental overstimulation. Capacitors were linked in series to the electrode outputs to provide protection against DC current flow from the stimulator unit. The stimulator was powered by a single $1.5 \mathrm{~V}$ AA cell, from which a $+5 \mathrm{~V}$ supply, regulated by an integrated circuit voltage regulator was derived. In the first prototype, a $+100 \mathrm{~V}$ stimulator supply was derived from a parallel-fed Cockcroft-Walton voltage multiplier. The voltage multiplier was driven from a square wave oscillator, which generated two outputs 180 degrees apart in phase. The frequency of operation and the component values were selected so that the high voltage would collapse if a sustained load was applied to the output through failure of the other components. In the second-generation prototype, where the speech processor and stimulator circuitry were incorporated into a single package, the $100 \mathrm{~V}$ supply was produced by a switching power supply. The output impedance of the $100 \mathrm{~V}$ supply was still sufficiently high for the voltage to fall to approximately $12 \mathrm{~V}$ within a few $\mathrm{ms}$ if a low impedance was placed continuously across the output. The DC current for a $1,000 \mathrm{ohm}$ resistance would therefore be about $12 \mathrm{~mA}$, which is still within accepted safe levels for electrocutaneous stimulation. The $1.5 \mathrm{~mA}$ output current was controlled by a field-effect transistor (FET) which functioned as a current-limiter. In addition, a constant current-limiting diode was fitted to the output of the stimulator unit. All internal components were functionally insulated where possible, and waterproofing was applied to the entire power supply and the electrode handset cable connections.

\section{Operator Error or Misuse}

Maximum pulse width was limited to $1,000 \mu$ s through the computer interfacing program. Increase in levels during setting of $\mathrm{T}$ and $\mathrm{C}$ pulse widths was controlled by the subject through an intensity control knob. Subjects were instructed prior to the setting of the $\mathrm{C}$ pulse widths to choose a level which would feel comfortable for continuous stimulation, rather than a level which verged on discomfort. Accidental supra-C-width stimulus pulses could be produced by overzealous turning of the intensity control knob. While this might prove uncomfortable, no tissue damage would occur due to the current limiting described previously.

The device was housed in a strong plastic case, with protective covers over access screws, and connections protected from mechanical hazards. No breakage of the plastic units has occurred. The microphone cable was encased in a flexible plastic sheath and was electrically shielded. The cable from speech processor/stimulator to handset was constructed with a tough flexible plastic outer coating and a braided metal internal electrical shield, thereby providing protection for the internal wires.

Independent biomedical engineering analyses stated that the first-generation Tickle Talker met requirements of Australian Standard AS3200 (Electromedical Equipment) as a Class III device, which is the most intrinsically safe category of equipment (i.e., extra-low voltage powered). With that device, input signals from the outside world were transmitted into it via an isolation transformer, maintaining isolation of the user circuit from any earth-referenced source. The user circuit was further isolated by capacitive coupling, preventing leakage of DC currents to the user. In the present generation Tickle Talker, the isolation transformer has been replaced by opto-couplers.

\section{SAFETY CONSIDERATIONS IN LONG-TERM DEVICE USE}

Seven normally-hearing and four hearing-impaired adult subjects participated in the safety studies. The normally-hearing subjects were all university students and were paid for their participation. The four hearing-impaired subjects had been referred from the cochlear implant program at the University of Melbourne after failing to meet selection criteria for implantation. The safety studies were conducted concurrently with laboratory and field evalua- 
Journal of Rehabilitation Research and Development Vol. 29 No. 1 Winter 1992

Table 1.

Index finger temperatures for six normally-hearing subjects measured pre- and post-electrotactile stimulation for both stimulated (St) and unstimulated (NSt) index fingers.

\begin{tabular}{|c|c|c|c|c|c|c|c|}
\hline \multirow[b]{3}{*}{ Subjec } & \multirow[b]{3}{*}{ Trial } & \multicolumn{6}{|c|}{ Temperature $\left({ }^{\circ} \mathrm{C}\right)$} \\
\hline & & \multicolumn{2}{|c|}{ Pre-Stim } & \multicolumn{2}{|c|}{ Post-Stim } & \multicolumn{2}{|c|}{ Pre/Post Diff } \\
\hline & & St & NSt & $\mathbf{S t}$ & NSt & $\mathbf{S t}$ & NSt \\
\hline \multirow[t]{2}{*}{1} & 1 & 35 & 35 & 33 & 33 & -2 & -2 \\
\hline & 2 & 35 & 35 & 35 & 35 & 0 & 0 \\
\hline \multirow[t]{2}{*}{2} & 1 & 22.5 & 23 & 22.5 & 23 & 0 & 0 \\
\hline & 2 & 23 & 23 & 21 & 23 & -2 & 0 \\
\hline \multirow[t]{2}{*}{3} & 1 & 22 & 23 & 26.5 & 30 & +4.5 & +7 \\
\hline & 2 & 35 & 35 & 35 & 34 & 0 & -1 \\
\hline \multirow[t]{2}{*}{4} & 1 & 36.5 & 36 & 28 & 28.5 & -8.5 & -7.5 \\
\hline & 2 & 35 & 34 & 28 & 29 & -7 & -5 \\
\hline \multirow[t]{2}{*}{5} & 1 & 35 & 35 & 32 & 33 & -3 & -2 \\
\hline & 2 & 33 & 33 & 31.5 & 31 & -1.5 & -2 \\
\hline \multirow[t]{2}{*}{6} & 1 & 35.5 & 35 & 34.5 & 33.5 & -1 & -1.5 \\
\hline & 2 & 28.5 & 30 & 26 & 28 & -2.5 & -2 \\
\hline Mean & & 31.3 & 31.4 & 29.4 & 30.1 & -1.9 & -1.3 \\
\hline
\end{tabular}

tion of the prototype device as a speech perception aid with the same subjects (22). As part of this training and evaluation program, the seven normally-hearing subjects received 70 hours of clinical training with the electrotactile device over a 6 -month period. The hearing-impaired adults received 40 hours of clinical training (over 6 months), plus varying amounts of everyday use during the last 2 months of the training period. Subjects were free to choose not to participate in particular sections of the safety studies. In addition, two hearing-impaired adults who use the device as an everyday aid were assessed on a continuous basis over a 2-year period.

\section{Study 1: Effects on local tissue: Finger temperature}

Initial studies with the device found that skin temperature of the fingers in some individuals decreased by up to 3 degrees $\mathrm{C}$ following 30 minutes of electrotactile stimulation (20). These results suggested that the electrical stimulation was associated with some degree of vasoconstriction. Because of the potential implications of this as a side effect of the stimulus procedure, Study 1 was undertaken to quantify the prevalence and degree of skin cooling associated with longer-term use of the device.

\section{Procedure}

Finger temperature was measured for both the stimulated and nonstimulated index fingers for six normallyhearing subjects following completion of the 70-hour training and evaluation program. During the test session, temperature of the stimulated index finger was measured continuously with Yellow Springs Instruments (YSI-409 clinical thermometer and YSI-409A temperature probe). Initial recordings were made for 10 minutes with no stimulation to establish baselines for both stimulated and nonstimulated index fingers. Subsequently, 50 minutes of electrotactile stimulation was presented through the Tickle Talker, during which finger temperature of the stimulated index finger was continuously monitored. At the end of this period, temperature of the nonstimulated index finger was again measured. Trials were conducted on two different days for each of the six subjects. Input to the speech processor consisted of continuous speech prerecorded on audiocassette, and directly coupled to the input jack of the speech processor.

\section{Results}

Finger temperatures for the six normally-hearing subjects are shown in Table 1. Large variations in intersubject results are evident. In 8 of the 12 trials, cooling effects of 2.5 degrees $C$ or less were found. Subject 4 (both trials) shows larger cooling effects of between 5.0 to 8.5 degrees $C$ for both the stimulated and nonstimulated finger when post-stimulation temperatures are compared with prestimulation. In contrast, Subject 3 showed a poststimulation warming effect on trial 1 , for both the stimulated finger ( 4.5 degrees $C$ ) and nonstimulated finger (7.0 degrees C).

Since the temperature differences were not normally distributed, a Wilcoxon Matched-Pairs Signed Ranks Test was applied to the data. Comparison of stimulated index finger mean temperature with mean temperature of the unstimulated index finger prior to electrotactile stimulation showed a difference of 0.1 degrees C. Following electrotactile stimulation, the difference in mean temperature between the stimulated and nonstimulated index fingers had increased, with the stimulated index fingers showing a mean temperature 0.7 degrees $C$ cooler than the nonstimulated fingers. However, results of the Wilcoxon Test showed that the differences in skin temperature 
between the stimulated and unstimulated index fingers were not significant $(p>0.05)$, either prior to $(T=8.5, p=0.667)$ or following electrotactile stimulation $(T=13, p=0.142)$.

Comparison of mean temperatures from the prestimulation period with the post-stimulation period showed a cooling effect of -1.9 degrees $C$ for the stimulated index fingers, and -1.3 degrees $C$ for the nonstimulated fingers. Results of the Wilcoxon Test showed that these pre/poststimulation differences were not significant $(p>0.05)$, for either the stimulated index finger $(T=7, p=0.066)$, or nonstimulated finger $(T=8, p=0.088)$.

\section{Discussion}

Although large inter- and intrasubject variability was evident, comparison of pre- and post-stimulation temperatures did not show a significant cooling effect for either the stimulated or nonstimulated index fingers in the group of subjects tested. Most subjects showed cooling effects of less than two degrees, well within the range of normal everyday fluctuations. However, Subject 4 showed a greater cooling effect in both hands on both trials. Closer examination of the calculated Wilcoxon test statistics for the preversus post-stimulation comparisons suggests the presence of a marginally significant cooling effect, especially in the case of the stimulated index finger, if a lower confidence level was accepted. Since our main concern was to limit the possibility of a Type II error (i.e., accepting that no cooling effect existed, when in fact it does), it would be appropriate in this case to accept a higher level of statistical significance. The possibility that some individuals (e.g., Subject 4) might be particularly susceptible to the effect must also be considered.

The most likely explanation for the observed cooling is vasoconstriction of unknown etiology, resulting in reduced blood flow to the skin surface. Because similar degrees of cooling were recorded for both the stimulated and unstimulated fingers in affected individuals, the possibility of sympathetic reflexive action must be considered. An increase in sympathetic reflexive activity could also result in elevation of mean arterial pressure and heart rate in affected individuals. Given the results of the statistical tests, the large cooling effects noted in some subjects, and the possible long-term side effects if sympathetic reflex activity was involved, a more detailed study to clarify the prevalence and causative factors of the observed finger cooling was considered necessary.

\section{Study 2: Effect on local tissue: Vascular circulation}

The goal of Study 2 was to quantify the degree of any vasoconstrictive effects in the fingers and hand under more controlled conditions, and clarify causative factors for any observed vasoconstriction in individual subjects.

\section{Procedure}

Five normally-hearing subjects participated in the vascular study. Subjects were screened for a history of cold intolerance or Raynaud's phenomenon, presence of cardiac arrhythmias, implanted pacemakers, or previous epileptic episodes. None of the subjects in the study were found to exhibit any of these conditions.

Analysis of vascular circulation in the hand and fingers of each subject was conducted after 3 months of training with the electrotactile device. Several measures were performed: 1) hand blood flow, measured by water plethysmography, at ambient hand temperatures of 20 degrees $\mathrm{C}$ and 40 degrees $C$, after body heating to abolish cutaneous sympathetic activity, and after the cold pressor test induced by placement of ice on the neck; 2) finger blood flow, measured by strain gauge plethysmography, at temperatures of 20 degrees $\mathrm{C}$ and 40 degrees $\mathrm{C}$, and after body heating; and, 3) heart rate and blood pressure measured using a Dynamap $^{\mathrm{TM}}$ automatic recording device.

All procedures were conducted in a controlled laboratory environment with an air temperature of approximately 23 degrees C. Subjects were recumbent for all procedures. The hand wearing the electrotactile device was placed in a water-filled plethysmograph at a level slightly above the right atrium, and a sphygmomanometer cuff, which could be inflated and deflated by an automatic device, was placed around the wrist. A cuff connected to a Dynamap automatic blood pressure recording device was placed on the contralateral arm. Hand blood flow (HBF) was measured at plethysmograph temperatures of 20 degrees $\mathrm{C}$ and 40 degrees C. After recording of the resting HBF measurements, a cold pressor test was performed at each plethysmograph temperature by placing a cube of ice on the neck for 10 seconds before inflation and 50 seconds after inflation. Body temperature was then raised by placing the subject between two electric blankets-a Space Blanket ${ }^{\text {TM }}$ on top, and a second blanket wrapped around the head to prevent heat loss. Heating was continued until oral temperature had risen by 1 degree $C$ or until frank sweating was evident. HBF was again measured at a plethysmograph temperature of 40 degrees $C$, and the cold pressor test repeated.

After measurement of each of these parameters in the pre-stimulation condition, the effects of electrotactile stimulation on the parameter were recorded. Input to the Tickle Talker consisted of continuous speech prerecorded on audiocassette and directly coupled to the input socket of the device. 
Journal of Rehabilitation Research and Development Vol. 29 No. 1 Winter 1992

Table 2.

Hand blood flow measured at plethysmograph temperatures of $20^{\circ} \mathrm{C}$ and $40^{\circ} \mathrm{C}$, and after body heating, at rest and during the cold pressor test, prior to and during electrotactile stimulation.

\begin{tabular}{ccccccc}
\hline & \multicolumn{2}{c}{$\mathbf{2 0}^{\circ} \mathbf{C}$} & \multicolumn{2}{c}{$\mathbf{4 0}^{\circ} \mathbf{C}$} & \multicolumn{2}{c}{ Body Heating } \\
Subject & Pre & Stim & Pre & Stim & Pre & Stim \\
\hline Rest & & & & & & \\
1 & 1.6 & 1.5 & 12.5 & 10.7 & 23.2 & 26.9 \\
2 & 3.4 & 3.5 & 15.8 & 13.2 & 46.5 & 40.5 \\
3 & 2.7 & 2.0 & 11.7 & 11.9 & 41.5 & 38.2 \\
4 & 2.1 & 1.8 & 14.0 & 12.9 & 32.1 & 34.9 \\
5 & 1.3 & 1.4 & 9.3 & 10.2 & 25.6 & 20.2 \\
Mean & 2.22 & 2.04 & 12.84 & 11.78 & 33.78 & 32.14 \\
Cold Pressor & & & & & & \\
1 & 0.5 & 0.6 & 4.7 & 4.9 & 14.0 & 11.2 \\
2 & 1.3 & 1.6 & 6.3 & 7.8 & 16.2 & 15.0 \\
3 & 1.8 & 1.1 & 3.8 & 1.4 & 18.3 & 19.1 \\
4 & 0.4 & 0.2 & 6.8 & 3.3 & 18.1 & 16.2 \\
5 & 0.4 & 0.8 & 3.6 & 2.7 & 11.2 & 10.3 \\
Mean & 0.98 & 0.86 & 5.04 & 4.02 & 15.56 & 14.36 \\
\hline
\end{tabular}

All values are in $\mathrm{ml} / 100 \mathrm{ml} / \mathrm{min}$.

\section{Results}

Table 2 shows results for measurements of HBF in $\mathrm{ml} / 100 \mathrm{ml} / \mathrm{min}$, recorded both prior to and during electrotactile stimulation for three different temperature environments, and during the cold pressor test.

In all five subjects, HBF increased with increasing plethysmograph temperature. Addition of body heating (with the plethysmograph maintained at 40 degrees C) resulted in a further marked increase in flow. Following application of electrotactile stimulation, there was a small reduction in mean HBF for all three temperature environments. However, large inter- and intrasubject variations are evident in the data. Results of three-way analysis of variance (ANOVA) with temperature environment, presence/ absence of electrotactile stimulation, and resting or cold pressor test as main factors showed no significant differences between mean HBF during absence or presence of electrotactile stimulation $\left(F^{(1,48)}=0.6407\right.$, NS at $\left.p>0.05\right)$. However, results showed a significant difference in mean HBF measured across the three temperature environments $\left(F^{(2,48)}=149.05, p<0.001\right)$. Post-hoc analysis using the Neumann-Keuls procedure showed that the means for the three temperature environments were significantly differ- ent $(p<0.05)$, with a rank order of 20 degrees $C<40$ degrees $\mathrm{C}<$ body heating.

In all subjects, application of the cold pressor test resulted in an immediate reduction in HBF, both prior to and during electrotactile stimulation, and in all three temperature environments $\left(F^{(1,48)}=68.51, p<0.001\right)$.

Table 3 shows the ratio of HBF during the cold pressor test expressed as a percentage of preceding resting flow both prior to and during electrotactile stimulation for the five subjects. The ratios of reduction were relatively consistent between conditions and temperatures. Results of twoway ANOVA with absence/presence of electrotactile stimulation and temperature environment as main factors showed no significant differences in the cold pressor $\mathrm{HBF}$ ratios for either stimulus condition $\left(F^{(1,24)}=0.431\right.$, NS $p>0.05)$ or temperature environment $\left(F^{(2,24)}=1.22\right.$, NS $p>0.05$ ).

Table 4 shows finger blood flow (FBF) $(\mathrm{ml} / 100 \mathrm{ml} /$ $\mathrm{min}$ ) measured prior to and during electrotactile stimulation in the three temperature environments. As shown, there was a slight reduction in FBF at all three temperatures tested, with mean FBF varying to a larger degree in the higher temperature environments. Two-way ANOVA did not show any significant difference in mean FBF for stimulation condition $\left(F^{(1,24)}=1.07\right.$, NS $\left.p>0.05\right)$. However, large inter- and intrasubject variations were evident. Two-way ANOVA did show a significant effect of temperature environment on finger blood flow levels $\left(F^{(2,24)}=109.19\right.$, $p<0.001$ ). Post-hoc comparison using the Neumann-Keuls procedure showed that each of the three temperature environment means were significantly different $(p<0.05)$, with the same rank order as for HBF.

Table 4 also shows mean arterial pressure (MAP, in $\mathrm{mmHg}$ ) and heart rate (HR, in beats/min) measured prior to and during electrotactile stimulation in all three temperature environments. As shown, mean MAP decreased slightly during body heating, both prior to and during electrotactile stimulation. Results of two-way analysis of

Table 3.

Hand blood flow during the cold pressor test as a percentage of preceding resting flow at plethysmograph temperatures of $20^{\circ} \mathrm{C}$ and $40^{\circ} \mathrm{C}$, and after body heating both prior to and during electrotactile stimulation.

\begin{tabular}{ccccccc}
\hline & \multicolumn{2}{c}{$\mathbf{2 0}^{\circ} \mathrm{C}$} & \multicolumn{2}{c}{$\mathbf{4 0}^{\circ} \mathrm{C}$} & \multicolumn{2}{c}{ Body Heating } \\
& Pre-Stim & Stim & Pre-Stim & Stim & Pre-Stim & Stim \\
\hline Mean & 44.8 & 41.8 & 38.9 & 33.7 & 47.9 & 45.2 \\
\hline
\end{tabular}

All values are in percent. 
Table 4.

Finger blood flow (FBF), mean arterial pressure (MAP), and heart rate $(\mathrm{HR})$ measured at plethysmograph temperatures of $20^{\circ} \mathrm{C}$ and $40^{\circ} \mathrm{C}$, and after body heating, prior to and during.

\begin{tabular}{|c|c|c|c|c|c|c|}
\hline \multirow{2}{*}{ Test/Subject } & \multicolumn{2}{|c|}{$20^{\circ} \mathrm{C}$} & \multicolumn{2}{|c|}{$40^{\circ} \mathrm{C}$} & \multicolumn{2}{|c|}{ Body Heating } \\
\hline & Pre-Stim & Stim & Pre-Stim & Stim & Pre-Stim & Stim \\
\hline \multicolumn{7}{|l|}{ FBF } \\
\hline 1 & 3.6 & 3.4 & 20.9 & 16.4 & 28.9 & 33.2 \\
\hline 2 & 5.8 & 6.1 & 25.7 & 22.7 & 48.3 & 39.6 \\
\hline 3 & 4.2 & 3.7 & 26.2 & 26.5 & 44.2 & 40.3 \\
\hline 4 & 4.3 & 4.0 & 23.8 & 21.7 & 39.6 & 37.3 \\
\hline 5 & 2.9 & 2.8 & 16.4 & 15.8 & 31.2 & 25.1 \\
\hline Mean & 4.16 & 4.0 & 22.6 & 20.6 & 38.4 & 35.1 \\
\hline \multicolumn{7}{|l|}{ MAP } \\
\hline 1 & 80 & 80 & 78 & 79 & 74 & 73 \\
\hline 2 & 76 & 76 & 74 & 73 & 73 & 74 \\
\hline 3 & 85 & 85 & 85 & 88 & 80 & 80 \\
\hline 4 & 84 & 85 & 83 & 86 & 80 & 75 \\
\hline 5 & 82 & 83 & 80 & 79 & 79 & 83 \\
\hline Mean & 81.4 & 81.8 & 80 & 81 & 77.4 & 77 \\
\hline \multicolumn{7}{|l|}{ HR } \\
\hline 1 & 68 & 69 & 71 & 73 & 89 & 87 \\
\hline 2 & 66 & 65 & 69 & 69 & 92 & 95 \\
\hline 3 & 64 & 64 & 65 & 69 & 84 & 82 \\
\hline 4 & 67 & 70 & 72 & 73 & 89 & 92 \\
\hline 5 & 67 & 69 & 69 & 68 & 76 & 79 \\
\hline Mean & 66.4 & 67.4 & 69.2 & 70.4 & 86 & 87 \\
\hline
\end{tabular}

Finger blood flow values are in $\mathrm{ml} / 100 \mathrm{ml} / \mathrm{min}$, mean arterial pressure in $\mathrm{mmHg}$, and heart rate in beats/min.

variance showed no significant effect on MAP for either stimulus condition $\left(F^{(1,24)}=0.044\right.$, NS $\left.p>0.05\right)$ or temperature environment $\left(F^{(2,24)}=2.752\right.$, NS $\left.p>0.05\right)$. During body heating, there was an increase in HR, for both stimulation conditions. Results of two-way ANOVA showed that although there was no effect of stimulus condition on HR $\left(F^{1,24)}=0.480\right.$, NS $\left.p>0.05\right)$, a significant effect was found for temperature environment $\left(F^{(2,24)}=62.99, p<0.001\right)$. Post-hoc comparison using the Neumann-Keuls procedure showed that mean HR was significantly increased $(p<0.05)$ after body heating.

\section{Discussion}

Previous studies (20) and Study 1 reported that electrotactile stimulation was associated with some degree of cooling of the skin of the fingers in some individuals. Reduction in $\mathrm{HBF}$ or FBF as a result of vasoconstriction was suggested as a potential reason for the observed cooling. Although results of the vascular study failed to demonstrate a significant group reduction in $\mathrm{HBF}$ or $\mathrm{FBF}$ during electrotactile stimulation, some individuals did evidence a minimal reduction. This vasoconstriction might be mediated by a number of mechanisms including: 1) direct excitation of sympathetic efferent nerve fibers; 2) stimulation of large somatic afferent fibers resulting in reflex vasoconstriction; 3) psychophysiological effects such as those shown in intense concentration; 4) changes in the relative ratio of blood flow between the arteriovenous anastomoses and nutritive capillary beds; or, 5) the stimulation might produce effects by mechanisms similar to those of "vibratory stimulation" as observed in vibration-induced white finger disease or Raynaud's disease.

Direct excitation of sympathetic efferent fibers is unlikely because the vasoconstriction effects reported in individuals in Study 1 were not confined to the fingers on which stimulation occurred. No sweating, increase in heart rate, or MAP was evident in Study 2 following electrotactile stimulation, as would be expected from direct stimulation of sympathetics. Threshold for postganglionic sympathetic efferents should also be substantially higher than for the larger myelinated touch/proprioceptive afferents, and in the same range as pain fibers. Therefore, stimuli adjusted for the touch afferents should be subthreshold for the sympathetic efferents. In addition, in Study 2 , cooling effects during electrotactile stimulation were noted by some individuals following body heating, which should have effectively abolished all sympathetic activity.

Transient vasoconstriction may be caused by any skin sensory stimulus: however, a repetitive touch stimulus would be unlikely to cause a sustained reflex vasoconstriction due to habituation effects (39). Vasoconstriction mediated by reflex effects could affect the contralateral hand, and the results of Study 1 did suggest cooling in both hands of affected subjects.

Psychophysiological effects such as those associated with mental arithmetic can cause quite sustained symmetrical vasoconstriction in the hands, usually associated with a rise in heart rate and blood pressure. Reductions in $\mathrm{HBF}$ from 3.3 to $2.9 \mathrm{ml} / 100 \mathrm{ml} / \mathrm{min}$ in cold, and from 14.4 to $8.7 \mathrm{ml} / 100 \mathrm{ml} / \mathrm{min}$ in warm conditions have been noted, together with increases in heart rate and MAP, indicating a marked increase in resistance to blood flow (39). While this might be a plausible explanation since intense concentration is required when using the device for supplementation of lipreading, subjects in Study 1 showed cooling of 
both hands, even though no concentration task was required and no increase in MAP or HR were evidenced during application of electrotactile stimulation in Study 2.

Pathological effects such as those associated with Raynaud's phenomenon or disease could be a potential explanation for the observed vasoconstriction noted. This cooling phenomenon, usually associated with hazards of vibrating tools, has several different theories as to causative factors. These include the sensitization of the arteries to noradrenalin as a result of mechanical vibration (40), or reflex effects originating from the pacinian corpuscles (41). However, one would expect to see enhanced vasoconstrictor response to local cooling at plethysmograph temperatures of 20 degrees $\mathrm{C}$, which was not evidenced in the cold pressor results across temperature environment. In addition, there was no evidence of structural changes during presence of electrotactile stimulation since HBF at maximal vasodilation during body heating was not significantly different from HBF in the pre-stimulation condition.

In summary, sympathetic efferent and pathological causes for the observed cooling and vasoconstriction noted in some individuals can be eliminated as contributing factors. The most likely explanation is that the electrotactile stimulation is altering some baseline condition in arteriovenous anastomoses, resulting in changes in the ratio of blood flow between the arteriovenous anastomoses and nutritive capillary beds. However, it must be stressed that no significant group effect was detected, and that the degree of reduction in HBF or FBF, or finger temperature cooling noted for individuals in Studies 1 and 2 was minimal, and should not be seen as a general limiting factor in the use of the device. It is suggested that potential users of the
Tickle Talker be screened for the presence of any scleroderma or white finger disease prior to using the device.

\section{Study 3: Effects on peripheral nervous system: $\mathrm{T} / \mathrm{C}$ pulse widths}

Initial studies with the Tickle Talker reported that threshold $(\mathrm{T})$ and maximum comfortable $(\mathrm{C})$ pulse widths selected by subjects showed some increase over time (20). Since a possible explanation for a rise in electrical thresholds could be due to physiological changes in tissue or nerve function, Study 3 aimed to quantify the prevalence and degree of any observed changes in $\mathrm{T}$ and $\mathrm{C}$ pulse widths following longer-term experience with electrotactile stimulation.

\section{Procedure}

Mean $\mathrm{T}$ and $\mathrm{C}$ pulse width levels for the eight electrodes were recorded for the seven normally-hearing subjects over the 6-month training period. The actual number of sessions recorded varied slightly between subjects, most notably in the case of Subject 3, who showed a marked change in $\mathrm{T}$ and $\mathrm{C}$ pulse widths following the introduction of a modified electrode geometry. Due to this change, additional measurements were made on this subject. Mean $\mathrm{T}$ and $\mathrm{C}$ pulse widths were also measured over time for five hearing-impaired adults using the device as an everyday aid. The number of recording sessions and the period over which the measurements were made varied from 6 to 36 months.

Subsequently, for GM and JC, who had received 24 and 36 months of training and experience with the device respectively, mean $\mathrm{T}$ and $\mathrm{C}$ pulse widths for the eight elec-
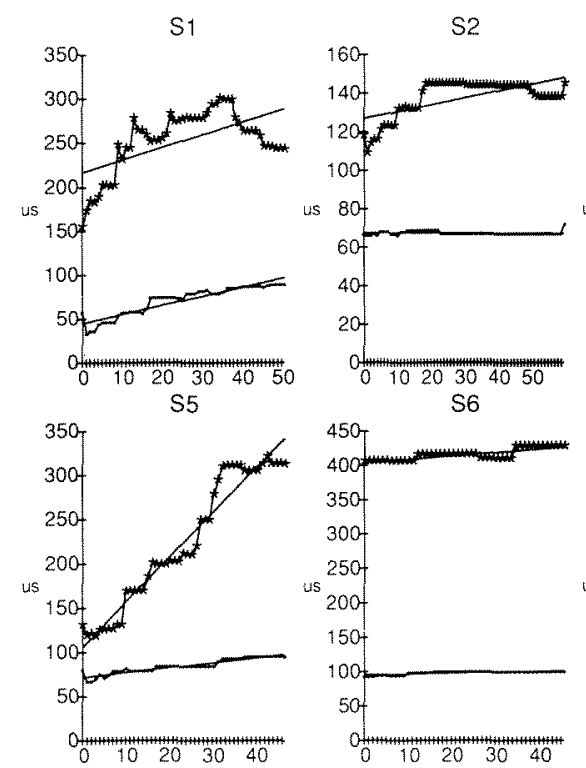

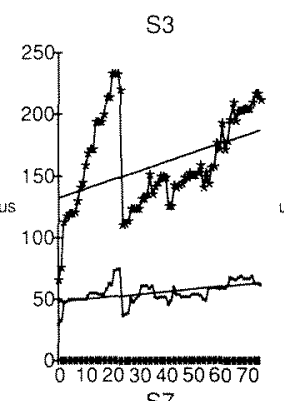

S7

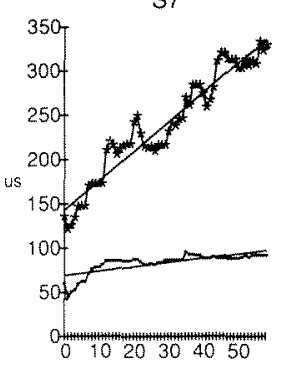

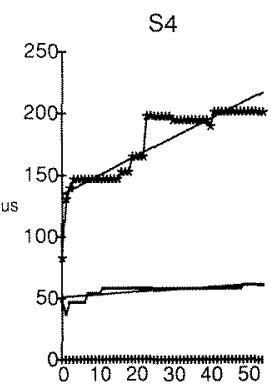

Figure 2.

Mean $\mathrm{T}$ and $\mathrm{C}$ pulse widths (eight electrodes in $\mu$ s/session) for seven normally-hearing subjects measured over a 6 -month period. 
COWAN et al. Electrotactile Speech Processor

Table 5.

Statistical data for regression line analysis of mean threshold $(\mathrm{T})$ and comfortable $(\mathrm{C})$ pulse widths for seven normally-hearing and five hearing-impaired adult subjects.

\begin{tabular}{|c|c|c|c|c|c|c|c|}
\hline Subject & $\begin{array}{c}\mathbf{n} \\
\text { (sessions) }\end{array}$ & $\begin{array}{c}\text { Time } \\
\text { (months) }\end{array}$ & Level & $\begin{array}{c}\text { Corr.Coeff. } \\
(\mu / \text { session })\end{array}$ & $\begin{array}{c}\text { Slope } a \\
(\mu / \text { month })\end{array}$ & $t$-stat. $a$ & Slope $c$ \\
\hline \multirow[t]{2}{*}{1} & 50 & 6 & $\mathrm{~T}$ & 0.933 & 1.037 & 18.106 & 8.642 \\
\hline & & & $\mathrm{C}$ & 0.604 & 1.435 & 5.299 & 11.958 \\
\hline \multirow[t]{2}{*}{2} & 59 & 6 & $\mathrm{~T}$ & -0.092 & -0.005 & -0.705 & -0.049 \\
\hline & & & $\mathrm{C}$ & 0.647 & 0.359 & 6.455 & 3.530 \\
\hline \multirow[t]{2}{*}{3} & 75 & 6 & $\mathrm{~T}$ & 0.519 & 0.206 & 5.228 & 2.575 \\
\hline & & & $\mathrm{C}$ & 0.429 & 0.729 & 4.079 & 9.113 \\
\hline \multirow[t]{2}{*}{4} & 54 & 6 & $\mathrm{~T}$ & 0.710 & 0.028 & 7.346 & 0.252 \\
\hline & & & $\mathrm{C}$ & 0.886 & 1.534 & 13.883 & 13.806 \\
\hline \multirow[t]{2}{*}{5} & 46 & 6 & $\mathrm{~T}$ & 0.941 & 0.554 & 18.596 & 4.247 \\
\hline & & & $\mathrm{C}$ & 0.974 & 5.146 & 28.631 & 39.452 \\
\hline \multirow[t]{2}{*}{6} & 45 & 6 & $\mathrm{~T}$ & 0.774 & 0.134 & 8.097 & 1.005 \\
\hline & & & C & 0.815 & 0.512 & 9.319 & 3.84 \\
\hline \multirow[t]{2}{*}{7} & 58 & 6 & $\mathrm{~T}$ & 0.747 & 0.487 & 8.483 & 4.701 \\
\hline & & & $\mathrm{C}$ & 0.962 & 3.335 & 26.665 & 32.238 \\
\hline \multirow[t]{2}{*}{$\mathrm{JC}$} & 89 & 36 & $\mathrm{~T}$ & 0.704 & 0.735 & 9.308 & 1.817 \\
\hline & & & C & 0.904 & 2.973 & 19.787 & 7.349 \\
\hline \multirow[t]{2}{*}{ PL } & 56 & 12 & $\mathrm{~T}$ & 0.931 & 1.600 & 18.833 & 7.467 \\
\hline & & & $\mathrm{C}$ & 0.874 & 5.374 & 13.322 & 25.079 \\
\hline \multirow[t]{2}{*}{ PB } & 47 & 12 & $\mathrm{~T}$ & 0.278 & 0.094 & 1.959 & 0.368 \\
\hline & & & $\mathrm{C}$ & 0.149 & 0.144 & 1.022 & 0.564 \\
\hline \multirow[t]{2}{*}{ SS } & 22 & 6 & $\mathrm{~T}$ & 0.425 & 0.195 & 2.152 & 0.715 \\
\hline & & & $\mathrm{C}$ & 0.923 & 3.284 & 10.952 & 12.04 \\
\hline \multirow[t]{2}{*}{ GM } & 54 & 24 & $\mathrm{~T}$ & -0.459 & -1.237 & -3.765 & -2.78 \\
\hline & & & C & -0.625 & -4.952 & -5.823 & -11.14 \\
\hline
\end{tabular}

Slope $a$ is uncorrected slope of regression lines shown in Figures 2 and $3 ; t$-stat. $a$ is confidence interval on that slope; slope $c$ is slope of regression line corrected for number of months over which session measurements were taken.

trodes on the stimulated hand were compared with pulse widths measured on the hand which had not previously received electrotactile stimulation. Similar measurements of stimulated and nonstimulated hand mean $\mathrm{T}$ and $\mathrm{C}$ pulse widths were made for three normally-hearing members of the research staff with long-term exposure to electrotactile stimulation provided through the device.

Results

Figure 2 shows mean $\mathrm{T}$ and $\mathrm{C}$ pulse widths for eight 

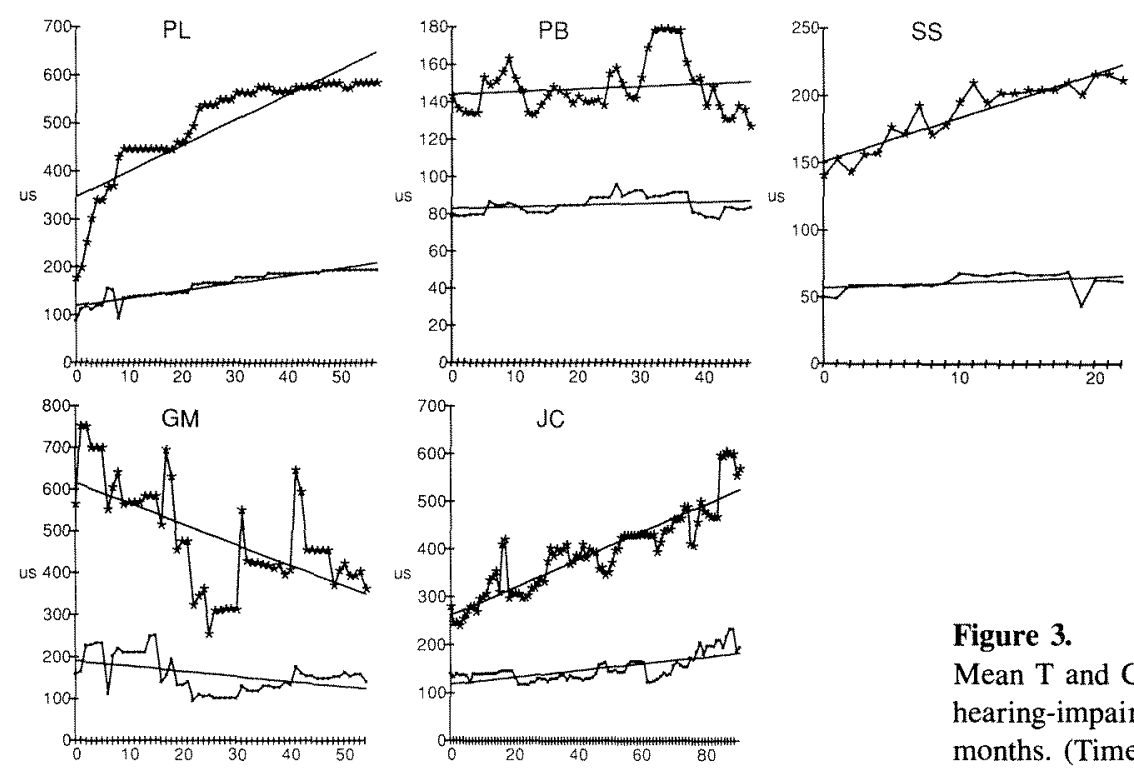

electrodes recorded over the 6-month period for the seven normally-hearing subjects (Subject 1-Subject 7). Visual inspection of the graphs shows variation in mean $\mathrm{T}$ pulse widths over this period to be less than for $\mathrm{C}$ pulse widths for all subjects. Overall, mean $\mathrm{T}$ pulse widths show little increase over the recording period, while changes in mean $C$ pulse widths vary between subjects.

Results of statistical analysis, shown as Table 5, indicate a significant increase in mean $\mathrm{T}$ and $\mathrm{C}$ pulse widths over time (i.e., significant upward slope of the best fit regression line $p<0.05$ ), for all normally-hearing subjects except Subject 2 ( $\mathrm{T}$ pulse widths only). As shown, slope of the regression line (in $\mu$ s/session) was greater for mean $C$ pulse widths than for mean $T$ pulse widths for all of the subjects. As the number of sessions varied slightly between subjects, a corrected slope value (in $\mu \mathrm{s} /$ month) was calculated to allow more accurate comparison of changes over time, and these values are also shown in Table 5. This was calculated according to the formula:

$$
\text { corrected slope } c=\frac{\text { slope } a \times \text { number of sessions }}{\text { number of months training }}
$$

Corrected slopes for mean $\mathrm{T}$ pulse widths showed changes from -0.049 to $8.64 \mu \mathrm{s} /$ month, while changes in mean C pulse widths ranged from 3.53 to $39.45 \mu \mathrm{s} /$ month, confirming the visual observations that changes in mean $\mathrm{T}$ pulse widths were less than for mean $\mathrm{C}$ pulse widths.

Similar data for five hearing-impaired adults is shown in Figure 3 and Table 5. Variations in mean $\mathrm{C}$ pulse widths were greater than for mean thresholds, and significant

increases in both $\mathrm{T}$ and $\mathrm{C}$ pulse widths were measured over varied time periods for all subjects except $\mathrm{PB}$ (both $\mathrm{T}$ and C), SS ( $T$ only), and GM (both T and C). In four of the adults (PL, PB, SS, JC) slope of the mean C pulse width regression lines (in $\mu \mathrm{s} / \mathrm{session}$ ) were much greater than for mean thresholds. Comparison of changes in corrected slope measured in $\mu \mathrm{s} /$ month for these four adults shows a range of 0.368 to $7.467 \mu \mathrm{s} /$ month for mean T pulse widths, and 0.564 to $25.079 \mu \mathrm{s} /$ month for mean $\mathrm{C}$ pulse widths. These values are similar to those recorded for the normallyhearing subjects.

Mean $\mathrm{T}$ and $\mathrm{C}$ pulse widths recorded for hearingimpaired subject GM, who has participated in training and used the device over a period of 2 years, show a different pattern of change from those of the other normally-hearing subjects and hearing-impaired adults, in that both mean $\mathrm{T}$ and $\mathrm{C}$ pulse widths decreased over time.

Table 6 shows a comparison of mean $T$ and $C$ pulse widths for the stimulated and nonstimulated hands for $\mathrm{GM}$ and JC, who had received respectively 24 and 36 months of training and experience, and for three normally-hearing adults (members of the research staff) with extensive electrotactile experience. Mean $T$ and $C$ pulse widths were similar in the stimulated and nonstimulated hands subsequent to extensive long-term experience with the device for all subjects except GM. Results of paired $t$-tests showed that the differences between mean pulse widths for the stimulated and nonstimulated fingers were not significant for either mean T pulse widths $(t=2.54, d f=4$, NS $p>0.05)$ or mean C pulse widths $(t=1.24, d f=4$, NS $p>0.05)$. GM, 
Table 6.

Comparison of mean $\mathrm{T}$ and $\mathrm{C}$ pulse widths in the stimulated (St) and non-stimulated (NSt) hands for 2 hearing-impaired and 3 normally-hearing adults.

\begin{tabular}{|c|c|c|c|c|}
\hline \multirow[b]{2}{*}{ Subject } & \multicolumn{2}{|c|}{ Mean T $(\mu s)$} & \multicolumn{2}{|c|}{ Mean $C(\mu s)$} \\
\hline & St & NSt & $\mathbf{S t}$ & NSt \\
\hline A & 102 & 113 & 197 & 194 \\
\hline B & 64 & 63 & 286 & 213 \\
\hline $\mathrm{C}$ & 288 & 315 & 474 & 485 \\
\hline GM & 118 & 127 & 429 & 235 \\
\hline $\mathrm{JC}$ & 186 & 197 & 553 & 568 \\
\hline Mean difference St-NSt & \multicolumn{2}{|c|}{-11.4} & \multicolumn{2}{|c|}{49} \\
\hline$p$ & \multicolumn{2}{|c|}{$\mathrm{NS}, p>0.05$} & \multicolumn{2}{|c|}{ NS, $p>0.05$} \\
\hline
\end{tabular}

who shows lower mean $\mathrm{C}$ pulse widths in the nonstimulated finger, noted during testing that the intensities set for the nonstimulated hand were subjectively lower than for his normally-used hand. However, the unfamiliarity of the different sensations experienced proved uncomfortable to $\mathrm{GM}$, and resulted in the setting of lower $\mathrm{C}$ pulse widths than those accepted for the normally-used left hand.

\section{Discussion}

$\mathrm{T}$ and $\mathrm{C}$ pulse widths for the eight electrodes may depend on a number of factors: 1) geometry of the electrode/skin interface; 2 ) electrode position relative to the nerve bundles; 3 ) subjective criteria used to set $\mathrm{T}$ and $\mathrm{C}$ levels; and, 4) sensitivity of nerve bundles to electrical current.

To a large extent, the first two factors could not be controlled in the experimental design, since exact positioning varied between sessions, and different electrode shapes and sizes were used throughout the study period for developmental reasons. Subjective criteria could also vary between sessions, especially as the users became experienced with the potential speech discrimination benefits available through use of the device. This would be expected in the case of the hearing-impaired adults, but the normallyhearing users were also quite enthusiastic about achieving the best connected discourse scores and overall performance. However, our main aim was to determine that there was no change in factor 4 , the sensitivity of the nerve bundles to electrical current, through comparison of mean thresholds in the stimulated versus unstimulated hands after long-term use of the device.

Recordings of mean $\mathrm{T}$ and $\mathrm{C}$ pulse widths, following prolonged experience with the device, showed that significant increases in mean $C$ pulse widths were evident for most subjects. Increases in mean $C$ pulse widths were overall greater than for T pulse widths. JC and GM, who were evaluated over a longer period, showed marked fluctuations in pattern for mean $\mathrm{T}$ and $\mathrm{C}$ pulse widths. As discussed, these individual variations may reflect effects of different electrode designs, geometry of the electrode/skin interface, or placement of the electrodes in relation to the position of the digital nerve bundles. During this period, three different models of handset and electrode size were tested. Effects of electrode surface area are seen clearly for Subject 3, who was provided with a new handset with slightly larger surface area electrodes after session 20 . In separate experiments, variations in both $\mathrm{T}$ and $\mathrm{C}$ mean pulse widths were found for electrodes differing in surface area, shape, and material of construction.

No significant differences were found between mean $\mathrm{T}$ and $\mathrm{C}$ pulse widths in the stimulated and nonstimulated hands for experienced long-term users of the device. This suggests that the increases shown were not due to physiological changes in the sensitivity of the digital nerve bundles in the stimulated hand as a result of exposure to electrotactile stimulation. The observed increase in mean $C$ pulse widths may be due to changes in the subjective criterion used by particular users in setting of $\mathrm{C}$ pulse widths as a "most comfortable level" in contrast to a discomfort level. The increase shown over time may reflect subjective changes such as acceptance of stronger stimuli as the users become more familiar with the sensation and the potential benefits available from the device. This would be consistent with the findings of similar $\mathrm{C}$ pulse widths in both the stimulated and unstimulated hands of the experienced users.

In contrast to the other subjects, GM shows a progressive decrease in mean $C$ pulse widths over time. In early work with $\mathrm{GM}$, repeated explanations were required to ensure that $C$ pulse widths were not set at discomfort levels to "ensure a clear signal." The decrease in mean C pulse widths for GM may reflect a more realistic subjective setting of pulse widths for long-term use of the device.

Overall, the results do not indicate any systematic change or habituation of mean $\mathrm{T}$ or $\mathrm{C}$ pulse width levels which would be consistent with changes in sensitivity of the digital nerve bundles in the stimulated hand subsequent to electrotactile stimulation presented through the Tickle Talker. However, long-term monitoring of mean $\mathrm{T}$ and $\mathrm{C}$ pulse widths will be continued with both children and adults using the Tickle Talker as an everyday speech perception aid. 
Journal of Rehabilitation Research and Development Vol. 29 No. 1 Winter 1992

\section{Study 4: Effects on peripheral nervous system: Tactual sensitivity}

Study 4 examined the effects of longer-term exposure to electrotactile stimulation on tactual sensitivity in the fingers of the stimulated hand. In a similar methodology to the initial finger temperature recordings reported in Study 1 , the tests were chosen for their simplicity and ease of application rather than as an in-depth analysis of tactual perception. A more detailed evaluation similar to that of Study 2 was planned if potentially significant effects which might limit long-term device use were suggested by the results of the initial measures.

\section{Procedure}

Three standard measures of tactual sensitivity were used: sharp-dull discrimination, hot-cold discrimination, and two-point difference limen. Measures were made on both the stimulated and nonstimulated index fingers for six normally-hearing subjects, subsequent to their completion of the training/evaluation program.

Sharp-dull distinctions were tested using alternate ends of a laboratory dissection pin as a stimulus. One end of the dissection pin was sharply pointed, while the opposite end was a flattened surface $\left(2 \mathrm{~mm}^{2}\right)$. Ten random-order $1 \mathrm{sec}$ presentations of both the sharp and dull stimulus were made to the index finger pad of both the stimulated and nonstimulated fingers.

Hot-cold sensitivity was measured in a similar manner, utilizing standard laboratory test tubes containing hot and cold water as stimuli. Ten random-order $1 \mathrm{sec}$ presentations of the hot and cold stimuli were made to the finger pad of the distal phalanx of both the stimulated and nonstimulated index fingers.

Two-point sensitivity was measured on the finger pad of the distal phalanx. Either one or both points of a twin-point compass were pressed on the pad for a period of $0.5 \mathrm{sec}$, and subjects were asked to respond with the number of points felt. Micrometer adjustments were made to the distance between points, which was increased until the subject consistently reported the stimulus as containing two points.

For each of the three tactual sensitivity measures, the subjects' hands were excluded from their visual field, and no feedback on correctness of response was given. Stimuli were presented prior to and immediately following 50 minutes of continuous electrotactile stimulation. Two separate trials for each of the kinesthetic sensitivity measures were conducted on different days for each of the six subjects. Input to the Tickle Talker was continuous speech, prerecorded on audiocassette, and directly coupled to the input socket of the device.
Table 7.

Sharp-Dull and Hot-Cold discrimination scores for six normallyhearing subjects measured pre- and post-electrotactile stimulation for both stimulated (St) and unstimulated (NSt) index fingers.

\begin{tabular}{|c|c|c|c|c|c|c|c|c|c|}
\hline \multirow{4}{*}{ Subject } & \multirow{4}{*}{ Trial } & \multicolumn{8}{|c|}{ Correct Discriminations $(\times / 10)$} \\
\hline & & \multicolumn{4}{|c|}{ Sharp/Dull } & \multicolumn{4}{|c|}{ Hot/Cold } \\
\hline & & \multicolumn{2}{|c|}{ Pre-Stim } & \multicolumn{2}{|c|}{ Post-Stim } & \multicolumn{2}{|c|}{ Pre-Stim } & \multicolumn{2}{|c|}{ Post-Stim } \\
\hline & & St & NSt & St & NSt & St & NSt & St & NSt \\
\hline \multirow[t]{2}{*}{1} & 1 & 10 & 10 & 10 & 10 & 10 & 10 & 10 & 10 \\
\hline & 2 & 10 & 10 & 10 & 10 & 10 & 10 & 9 & 9 \\
\hline \multirow[t]{2}{*}{2} & 1 & 10 & 10 & 10 & 9 & 10 & 10 & 10 & 10 \\
\hline & 2 & 10 & 9 & 10 & 9 & 10 & 10 & 10 & 10 \\
\hline \multirow[t]{2}{*}{3} & 1 & 10 & 10 & 10 & 10 & 10 & 10 & 10 & 10 \\
\hline & 2 & 10 & 10 & 10 & 10 & 10 & 10 & 10 & 10 \\
\hline \multirow[t]{2}{*}{4} & 1 & 9 & 10 & 10 & 10 & 10 & 10 & 10 & 9 \\
\hline & 2 & 10 & 9 & 10 & 10 & 10 & 10 & 10 & 10 \\
\hline \multirow[t]{2}{*}{5} & 1 & 10 & 9 & 10 & 9 & 10 & 10 & 10 & 10 \\
\hline & 2 & 10 & 10 & 10 & 10 & 10 & 10 & 10 & 10 \\
\hline \multirow[t]{2}{*}{6} & 1 & 10 & 10 & 10 & 10 & 10 & 10 & 10 & 10 \\
\hline & 2 & 10 & 10 & 10 & 10 & 10 & 10 & 10 & 10 \\
\hline
\end{tabular}

All values are in number of trials out of 10 .

\section{Results}

Table 7 and Table 8 show results for the three tactual sensitivity tests with the six normally-hearing subjects.

As shown in Table 7, no obvious differences in sharpdull, or hot-cold sensitivity were evident either for comparison of pre-stimulation versus post-stimulation results, or for comparison of the stimulated versus unstimulated hand for any of the subjects.

Results for two-point discrimination limens (Table 8) are more variable. Mean two-point discrimination limens were reduced for both the stimulated $(1.64 \mathrm{~mm}$ pre versus $1.43 \mathrm{~mm}$ post $)$ and nonstimulated finger $(1.6 \mathrm{~mm}$ pre versus $1.37 \mathrm{~mm}$ post) following the 50 -minute electrotactile stimulus period. Results of paired $t$-tests indicated that the differences between pre- and post-stimulation means were not significant for either the stimulated $(t=-1.345, d f=11$, NS $p>0.05)$ or unstimulated index finger $(t=-2.02, d f=11$, NS $p>0.05$ ). However, large intersubject variations were evident. For example, Subject 4 shows reductions in two-point limens post-stimulation for stimulated (both trials) and nonstimulated fingers (one trial), while Subjects 2 and 3 show 
Table 8.

Two-point discrimination limens measured for six normallyhearing subjects pre- and post-electrotactile stimulation for stimulated (St) and unstimulated (NSt) index fingers.

\begin{tabular}{|c|c|c|c|c|c|c|c|}
\hline \multirow[b]{3}{*}{ Subject } & \multirow[b]{3}{*}{ Trial } & \multicolumn{4}{|c|}{ Two-point Discrimination } & \multicolumn{2}{|c|}{ Limen (mm) } \\
\hline & & \multicolumn{2}{|c|}{ Pre-Stim } & \multicolumn{2}{|c|}{ Post-Stim } & \multicolumn{2}{|c|}{ Pre/Post Diff } \\
\hline & & St & NSt & St & NSt & St & NSt \\
\hline \multirow[t]{2}{*}{1} & 1 & 2.2 & 2.2 & 2.1 & 2.0 & -0.1 & -0.2 \\
\hline & 2 & 2.0 & 2.0 & 2.0 & 2.0 & 0 & 0 \\
\hline \multirow[t]{2}{*}{2} & 1 & 1.5 & 1.8 & 1.8 & 1.8 & +0.3 & 0 \\
\hline & 2 & 1.2 & 1.2 & 1.5 & 1.1 & +0.3 & -0.1 \\
\hline \multirow[t]{2}{*}{3} & 1 & 1.0 & 1.2 & 1.1 & 1.3 & +0.1 & +0.1 \\
\hline & 2 & 1.1 & 1.6 & 1.5 & 1.5 & +0.4 & -0.1 \\
\hline \multirow[t]{2}{*}{4} & 1 & 2.5 & 2.0 & 1.0 & 1.0 & -1.5 & -1.0 \\
\hline & 2 & 1.6 & 1.0 & 1.3 & 1.0 & -0.3 & 0 \\
\hline \multirow[t]{2}{*}{5} & 1 & 1.5 & 1.5 & 1.1 & 0.9 & -0.4 & -0.6 \\
\hline & 2 & 1.5 & 1.5 & 1.0 & 1.0 & -0.5 & -0.5 \\
\hline \multirow[t]{2}{*}{6} & 1 & 1.8 & 1.8 & 1.8 & 1.8 & 0 & 0 \\
\hline & 2 & 1.8 & 1.4 & 1.0 & 1.0 & -0.8 & -0.4 \\
\hline Mean & & 1.64 & 1.6 & 1.43 & 1.37 & -0.21 & -0.23 \\
\hline
\end{tabular}

$\mathrm{A}+$ for pre/post difference denotes an increase in two-point limen, while a - denotes a decrease; all values are in $\mathrm{mm}$.

small increases in two-point difference limens in the stimulated finger post-stimulation. A $t$-test comparing mean two-point difference limens for the stimulated and nonstimulated index fingers following electrotactile stimulation did not find any significant difference $(t=1.349, d f=11$, NS $p>0.05$ ).

\section{Discussion}

No significant changes were noted following electrotactile stimulation on either the sharp-dull or hot-cold tactual sensitivity measures. While a change was noted for some subjects on the two-point difference limen test, the mean effect was a reduction in difference limen, suggesting an increase in tactual sensitivity following electrotactile stimulation. This would not be consistent with any decrement in peripheral nerve function resulting from electrotactile stimulation.

Overall, the results of the three tactual sensitivity measures did not detect significant changes following electrotactile stimulation. While the tests are rather crude, it would be expected that any marked decrement in sensitivity resulting from electrotactile stimulation would be evident as a consistent pattern in the results. Given the findings, no further detailed study was considered necessary.

\section{Study 5: Effects on central nervous system: EEG recordings}

While it is unlikely that electrocutaneous stimulation would have detrimental effects on central nervous function, a factor relating to a specific hearing-impaired group who potentially might use the device necessitated an assessment. Many cases of early acquired severe-to-profound deafness are a result of meningitis. It is also well-known that meningitis and encephalitis are associated with an increased incidence of focal spike discharges and epilepsy $(42,43)$. Recent reports suggest that epilepsy occurs in 2 to 3 percent of children who have had previous meningitis, as compared with the generally accepted prevalence of epilepsy in the community of 0.5 to 1.0 percent $(44,45)$. Since epileptic episodes may result from repetitive external stimuli (e.g., photic stimuli), an examination of the effects of continuous electrotactile stimulation on electroencephalographic (EGG) recordings was undertaken to investigate the possibility that the electrical stimulation could act as an activator for focal discharges.

\section{Procedures}

Standard EEG recordings (46) were made in sessions prior to, during, and immediately following cessation of electrotactile stimulation of the digital nerves of the hand with output from the Tickle Talker. Seven normally-hearing and three hearing-impaired subjects participated in this study. As with the other studies, continuous speech input was prerecorded on audiocassettes, and presented through a Sony Walkman, which was directly coupled to the input socket on the Tickle Talker. EEGs were recorded while the subjects were resting, with eyes open, eyes closed, during hyperventilation, and with photic stimulation. Each recording was approximately $20 \mathrm{~min}$ long and made on a 16-channel EEG machine, utilizing from 10 to 20 Montage positions with bipolar, average reference, and source derivation recordings. Each of the seven normally-hearing subjects had three recording sessions, the first one prior to exposure to electrotactile stimulation, the second following 35 hours of training with the device, and a third following an additional 35 hours of training. Hearingimpaired subjects had two recording sessions, one prior to electrotactile training, and one following 40 hours of training in use of the device. As discussed, each of the hearing-impaired adults also used the processor for variable amounts of additional time as an everyday aid during this 
Journal of Rehabilitation Research and Development Vol. 29 No. 1 Winter 1992

Table 9.

Analysis of EEG recordings for seven normally-hearing and four hearing-impaired subjects prior to electrotactile training, and after three and six months electrotactile experience.

\begin{tabular}{lcccccccccc}
\hline Session & & & \multicolumn{1}{c}{ Subject } & & & & \\
& $\mathbf{1}$ & $\mathbf{2}$ & $\mathbf{3}$ & $\mathbf{4}$ & $\mathbf{5}$ & $\mathbf{6}$ & $\mathbf{7}$ & $\mathrm{JC}$ & $\mathbf{P B}$ & PL \\
\hline 1st EEG & $\mathrm{HV}+$ & $\mathrm{U}$ & $\mathrm{HV}+$ & $\mathrm{U}$ & $\mathrm{U}$ & $\mathrm{U}$ & $\mathrm{U}$ & $\mathrm{U}$ & $\mathrm{U}$ & $\mathrm{U}$ \\
2nd EEG HV+ & $\mathrm{U}$ & $\mathrm{HV}+\mathrm{HV}+$ & $\mathrm{U}$ & $\mathrm{U}$ & $\mathrm{U}$ & $\mathrm{U}$ & $\mathrm{U}$ & $\mathrm{U}$ \\
3rd EEG & $\mathrm{U}$ & $\mathrm{U}$ & $\mathrm{HV}+\mathrm{HV}+$ & $\mathrm{U}$ & $\mathrm{U}$ & $\mathrm{HV}+$ & & & \\
\hline
\end{tabular}

$\mathrm{U}$ denotes unremarkable EEG, $\mathrm{HV}+$ denotes slow and/or sharp wave forms with or just after hyperventilation.

period. EEG recordings were visually analyzed in a "blind" random order by an experienced neurophysician.

Results

Table 9 shows results of the analysis of EEG tracings for the seven normally-hearing and three hearing-impaired subjects.

Results shown with a "U" indicate an unremarkable EEG, while HV+ is used where there was a prominent build-up of slow and/or sharp wave forms during or just after hyperventilation. As shown, $\mathrm{HV}+$ traces were found in two subjects at the first recording, in three subjects at the second, and in three subjects at the third. Subject 3 showed an $\mathrm{HV}+$ trace at all three recordings. However, no consistent pattern of $\mathrm{HV}+$ recordings was evident for the other subjects. No other difference or abnormality of EEG pattern was detected between successive EEG recordings.

\section{Discussion}

Results of the EEG study did not detect any systematic difference in recordings during or subsequent to electrotactile stimulation presented through the Tickle Talker. No paroxysmal activity of epileptic type, or other abnormality was evident in conjunction with the periods of electrotactile stimulation. The increase in slow or sharp waveforms associated with hyperventilation may reflect the vigor with which individual subjects performed hyperventilation. Activation of the electroencephalogram by hyperventilation arises as a result of the lowering of serum $\mathrm{CO}_{2}$ levels during increased expiration. This consequently results in a more alkaline blood $\mathrm{pH}$ (47). Hypocapnia and alkalosis increases the excitability of the cortical cells, and epileptic foci and other disturbances may be more clearly manifested. In normal adults, EEG changes in response to hyperventilation are minimal. Young adults may show a nonparoxysmal slowing of the EEG and occurrence of bilateral sharp waves during the second or third minute of hyperventilation, which disappear within 20 to $30 \mathrm{sec}$ of return to normal breathing (48). This is consistent with the results for hyperventilation shown by some of the subjects. However, these results do not suggest any consistent effect of the electrotactile stimulation on the EEG which might be construed as pathological, or predisposing to epileptic episodes.

\section{DISCUSSION}

The results indicate that the electrotactile stimulation provided through the Tickle Talker is safe for use. Analyses of the stimulus waveform, speech processor, and stimulator electric circuit layout, and handset/cabling design show that potential problems relevant to the electrical nature of the stimulus and device have been addressed, and that user safety has been ensured. Results of tactual, vascular, and neurological evaluations have shown no significant effects on local tissue, peripheral nervous system, or central nervous system function which might limit application of the device.

In addition to the data presented, 15 hearing-impaired children and 4 adults have now been using the device for periods of up to 3 years. Results show significant benefits in improving speech perception from use of the Tickle Talker for both children and adults $(11,49)$. No biomedical or safety problems were encountered by either hearingimpaired adults or children using the Tickle Talker as an everyday aid after periods exceeding two and one-half years of use. Despite some transient problems with wrist stimulation which were resolved by elimination of the common wrist electrode, all users accepted the device as an everyday communication aid.

While these results are encouraging, longer-term safety studies with the device are continuing because the potential for problems to arise after several years of electrotactile stimulation must be examined. As discussed, tactile sensory devices have a lengthy history, apparently without incidence of serious biomedical complications (50). However, given that few devices have achieved acceptance and everyday use by large numbers of subjects over many years, the safety aspects cannot be guaranteed. While hearing-impaired adults and parents of hearing-impaired children may be adequately informed and accept the potential risks after weighing the potential benefits to speech 
perception available through the use of a particular device, researchers and manufacturers have a clear responsibility to ensure the long-term safety of devices, especially those used by children. It is hoped that safety studies, similar to those conducted for cochlear prostheses and as reported in the present study, will become accepted practice for researchers involved in development of electrotactile and vibrotactile speech aids.

\section{ACKNOWLEDGMENTS}

The authors wish to express their gratitude to the adults, children, and their parents participating in the clinical development program. We wish to thank the technical staff of the Alfred Hospital Vascular Research Unit, and the Royal Childrens' Hospital Neurological Unit for their assistance in performing the in-depth studies. We also gratefully acknowledge the financial support of Cochlear Pty. Ltd., the Department of Industry, Technology and Commerce, and Department of Employment, Education and Training of the Australian Commonwealth Government, the National Health \& Medical Research Council, the Deafness Foundation (Victoria), the George Hicks Foundation, and the Ian Potter Foundation.

\section{REFERENCES}

1. Levitt H, Pickett JM, Houde RA, eds. Sensory aids for the hearing impaired. New York: IEEE Press, 1980.

2. Levitt $\mathbf{H}$. Hearing impairment and sensory aids: a tutorial review. J Rehabil Res Dev 1986;23(1):xiii-xviii.

3. Levitt $H$. Recurrent issues underlying the development of tactile sensory aids. Ear Hear 1988;9(6):301-5.

4. Sherrick CE. Basic and applied research on tactile aids for deaf people: progress and prospects. J Acoust Soc Am 1984;75:1325-41.

5. Berliner KI, Tonokowa LL, Dye LM, House WF. Open-set speech recognition in children with a single-channel cochlear implant. Ear Hear 1989;10:237-42.

6. Dawson PW, Blamey PJ, Rowland LC, Dettman SJ, Altidis P, Clark GM, et al. Speech perception, production and language results in a group of children using the 22 -electrode cochlear implant. Presented at the International Conference on Tactile Aids, Hearing Aids and Cochlear Implants. Sydney, Australia, May 1990.

7. Dorman MF, Hannley MT, Dankowski K, Smith L, McCandless G. Word recognition by 50 subjects fitted with the Symbion multichannel cochlear implant. Ear Hear 1989;10:444-9.

8. Dowell RC, Seligman PM, Whitford LA. Speech perception with the 22-channel cochlear prosthesis: a summary of ten years development. Presented at the International Conference on Tactile Aids, Hearing Aids and Cochlear Implants. Sydney, Australia, May 1990

9. Pickett JM, Stark RE. Cochlear implants and sensory aids for deaf children. Int J Pediatr Otorhinolaryngol 1987;13:323-44.

10. Cowan RSC, Blamey PJ, Alcántara JI, Whitford LA, Clark GM. Speech perception studies using a multichannel electrotac- tile speech processor, residual hearing, and lipreading. J Acoust Soc Am 1989;85:2593-2607.

11. Cowan RSC, Blamey PJ, Galvin KL, Sarant JZ, Alcántara JI, Clark GM. Perception of sentences, words and speech features by profoundly hearing-impaired children using a multichannel electrotactile speech processor. J Acoust Soc Am 1990;88:1374-82.

12. Lynch MP, Oller DK, Eilers RE. Portable tactile aids for speech perception. Volta Rev 1989;91(5):113-26.

13. Reed CM, Durlach NI, Delhorne LA, Rabinowitz WM, Grant KW. Research on tactual communication of speech: ideas, issues, and findings. Volta Rev 1989;91(5):65-78.

14. Weisenberger JM. Tactile aids for speech perception and production by hearing-impaired people. Volta Rev 1989;91(5):79-100.

15. Webb RL, Clark GM, Shepherd RK, Franz BK-H, Pyman BC. The biological safety of the Cochlear Corporation multipleelectrode intracochlear implant. Am J Otol 1988;9(1):8-13.

16. Cholewiak RW, Sherrick CE. Tracking skills of a deaf person with long-term tactile aid experience: a case study. J Rehabil Res Dev 1986;23(2):20-6.

17. Saunders FA, Hill WA, Simpson CA. Speech perception via the tactile mode: Progress report. In: Levitt H, Pickett JM, Houde RA, eds. Sensory aids for the hearing impaired. New York: IEEE Press, 1985:278-81.

18. Saunders FA, Franklin B: Field tests of a wearable 16-channel electrotactile sensory aid in a classroom for the deaf. J Acoust Soc Am 1985;78:S17.

19. Blamey PJ, Clark GM. A wearable multiple-electrode electrotactile speech processor for the profoundly deaf. J Acoust Soc Am 1985;77:1619-20.

20. Blamey PJ, Clark GM. Psychophysical studies relevant to the design of a digital electrotactile speech processor. J Acoust Soc Am 1987;82:116-25.

21. Pfeiffer EA. Electrical stimulation of sensory nerves with skin electrodes for research, diagnosis, communication and behavioral conditioning: a survey. Med Biol Eng 1968;6:637-51.

22. Cowan RSC, Alcántara JI, Blamey PJ, Clark GM. Preliminary evaluation of a multiple channel electrotactile speech processor. J Acoust Soc Am 1988;83:2328-38.

23. Seligman PM. Speech-processing strategies and their implementation. Ann Otol Rhinol Laryngol 1987;96 (Suppl 128):71-4.

24. Brummer SB, Turner MJ. Electrochemical considerations for safe electrical stimulation of the nervous system with platinum electrodes. IEEE Trans Biomed Eng 1977;BME-21:81-8.

25. Mason JL, MacKay NAM. Pain sensations associated with electrocutaneous stimulation. IEEE Trans Biomed Eng 1976;BME-23:405-9.

26. Rugerri RT, Beck TR. Calculations of temperature rise produced in body tissue by a spherical electrode. Ann Biomed Eng 1985;13:177-94.

27. Lilly JC. Brief non-injurious electric waveform for stimulation of the brain. Science 1955;121:468-9.

28. Cabanes J. Physiological effects of electric currents on living organisms, more particularly humans. In: Bridges JE et al., eds. Proceedings of the First International Symposium on Electric Shock Safety Criteria. Toronto: Pergamon Press, 1985.

29. Green HL, Ross J. Danger levels of short electric shocks from $50 \mathrm{~Hz}$ supply. In: Bridges JE et al., eds. Proceedings of the First International Symposium on Electric Shock Safety Criteria. Toronto: Pergamon Press, 1985. 
30. Shepherd RK, Clark GM, Black RC: Chronic electrical stimulation of the auditory nerve in cats. Acta Otolaryngol Suppl (Stockh) 1983;399:19-31.

31. Brummer SB, Roblee LS, Hambrecht FT. Criteria for selecting electrodes for electrical stimulation: Theoretical and practical considerations. Ann NY Acad Sci 1984;405:159-71.

32. Butikofer R, Lawrence PD. Electrocutaneous stimulation II: Stimulus waveform selection. IEEE Trans Biomed Eng 1979;BME-26:69-75.

33. Roblee LS, Cogan SF. Metals for metal electrodes. In: Cahn RW, ed. Encyclopedia of materials science and engineering. 1st supplement. New York: Pergamon Press, 1988:29-47.

34. Bergey GE, Squires RD, Simple RW. Electrocardiogram recording with pasteless electrodes. IEEE Trans Biomed Eng 1971;BME-18:206-11.

35. Lewes D. Multipoint electocardiography without skin preparation. Lancet 1965;2:17-18.

36. Ragheb T, Geddes LA. Electrical properties of metallic electrodes. IEEE Med Biol Eng Comp BMEC-28:182-6.

37. Gilson RH. Electrical stimulation of pain and touch. In: Kenshalo DR, ed. The skin senses. Springfield, IL: Charles C. Thomas Pub., 1968:223-61.

38. Burton C, Maurer DD. Pain suppression by transcutaneous electrical stimulation. IEEE Trans Biomed Eng 1974;BME-21:81-8.

39. Ludbrook $\mathbf{J}$, Vincent AH. The effects of mental arithmetic on hand blood flow. Aust J Biol Sci 1974;52:679-86.

40. Azuma T, Onhashi T, Sakaguchi M. Vibration-induced hyperresponsiveness of arterial smooth muscle to noradrenaline with special reference to Raynaud's phenomenon in vibration disease. Cardiovasc Res 1978;12:758-64.

41. Hyvarinen J, Pykko I, Sundberg S. Vibration frequency and ampli- tude in the aetiology of traumatic vasospastic disease. Lancet 1973;14:791-4.

42. Gibbs FA, Gibbs EL, Spies HW, Carpenter PR. Common types of childhood encephalitis: Electroencephalographic and clinical relationships. Arch Neurol 1964;10:1-11.

43. Trojaborg W. Focal spike discharges in children: A longitudinal study. Copenhagen: Laboratory of Clinical Neurophysiology, 1966:1-113.

44. Jadavji T, Biggar WD, Gold R, Proben CG. Sequel of acute bacterial meningitis in children treated for seven days. Pediatrics 1986;78:21-25.

45. Rosman NP, Peterson DB, Kaye EM, Cotton T. Seizures in bacterial meningitis: prevalence patterns, pathogenesis and prognosis. Pediatr Neurol 1985;1:278.

46. Gibbs FA, Gibbs EL. Medical electroencephalography. Reading, MA: Addison-Wesley Publishing Co., Inc., 1967.

47. Meyer JS, Gotoh F. Metabolic and electroencephalographic effects of hyperventilation. Arch Neurol 1960;3:539-552.

48. Schwab RS. Methods of activation of the electroencephalogram. In: Kugler J, ed. Electroencephalography in hospital and general consulting practice: an introduction. Amsterdam: Elsevier Science Publishing Co., Inc., 1964:54-63.

49. Cowan RSC, Blamey PJ, Sarant JL, Galvin KL, Alcántara JI, Whitford LA, Clark GM. Role of a multichannel electrotactile speech processor in a cochlear implant program for profoundlytotally deaf adults. Ear Hear 1991;12:39-46.

50. Sherrick CE. Tactual sound and speech-analyzing aids for deaf persons. In: Christman CL, Albert EN, eds. Cochlear implants: a model for regulation of emerging medical device technologies. Norwell, MA: Kluwer Academic Publishers (in press). 